Volume 2, Nomor 1, April 2021, hlm 27-33

JTTM: Jurnal Terapan Teknik Mesin

p ISSN 2721-5377| e ISSN 2721-7825

\title{
PERHITUNGAN KOMPRESI TRANSMISI (CONTINUOUSLY VARIABLE TRANSMISSION) PADA SEPEDA MOTOR MATIC 150 CC TRANSMISSION COMPRESSION CALCULATIONS (CONTINUOUSLY VARIABLE TRANSMISSION) ON A MATIC MOTORCYCLE 150 CC MOTORCYCLE
}

\author{
Bagas Imam Priambodo ${ }^{1}$, Hilman Sholih ${ }^{2}$, Firmansyah Azharul ${ }^{3 *}$ \\ 1,2,3* Program Studi Teknik Mesin Sekolah Tinggi Teknik Muhammadiyah Cileungsi \\ 1,2,3* J1. Anggrek, No 25, Komplek PT.SC, Cileungsi, Bogor, Jawa Barat-Indonesia 16820 \\ *Koresponden Email: firmansyah.azharul@sttmcileungsi.ac.id
}

\begin{abstract}
Abstrak. (Continuously variable transmission) CVT system adalah sistem transmisi ini tidak menggunakan roda gigi namun memanfaatkan sistem pulley and belt. Penelitian ini menganalisis komponen continuously variable transmission yaitu cara kerja CVT. Tujuan dari penelitian ini untuk mengetahui perhitungan berapa gaya sentrifugal. Dalam perhitungan ini menggunakan data aktual pada kendaraan bermotor yang menggunakan CVT. Adapun data dihasilkan oleh mesin dan jarak perpindahan atau pergeseran yang terjadi di pulley drive. Dari nilai yang didapat kecepatan maksimum 8500 RPM. Torsi 10.68984 Nm, kW 7.93275154, Gaya sentrifugal 60,6 Nm, Perpindahan $24,6 \mathrm{~mm}$.
\end{abstract}

Kata Kunci: Torsi, gaya sentrifugal, perpindahan pulley.

Abstract. CVT system (Continuously Variable Transmission) is a transmission system that uses a pulley and belt system, instead of using gears. The components of a continuously variable transmission are studied through this analysis, including how CVT functions. The object of this research was to decide the centrifugal force measurement. Usage of real data on motorized vehicles using CVT in this estimate. The object of this analysis was to decide the centrifugal force measurement. Usage of real motorized vehicle data using CVT in this estimation. The engine-generated details and the distance or displacement that takes place in the drive pulley. There is a top speed of $8500 \mathrm{RPM}$ from the value received. $10.68984 \mathrm{Nm}$ torque, $\mathrm{kW} 7.93275154,60.6 \mathrm{Nm}$ centrifugal force, displacement: $24.6 \mathrm{~mm}$.

Keywords: Torque, centrifugal force, pulley displacement.

\section{PENDAHULUAN}

Elemen transmisi kendaraan bermotor dewasa ini sudah menggunakan CVT system (Continuousuly Variable transmission), yang bekerja secara matik. Sebelumnya, elemen transmisi yang digunakan adalah rantai dan gear. Perkembangan teknologi kendaraan bermotor ini sesuai dengan kebutuhan masyarakat secara umum, yaitu agar mudah dioperasikan dan mudah dalam perawatan. Untuk mengetahui performanya, diperlukan perhitungan yang akurat mengenai elemen transmisi CVT system ini.

Upaya penelitian yang signifikan telah diarahkan pada pengembangan transmisi kendaraan yang mengurangi konsumsi energi fosil[1]. Upaya ini telah menjadi konsekuensi langsung dari meningkatnya kepedulian lingkungan untuk mengurangi emisi gas buang dan meningkatkan efisiensi kendaraan pada pabrikan dan pengguna kendaraan. Transmisi variabel kontinu (CVT) menawarkan 
rasio roda gigi yang kontinu antara batas yang diinginkan. Hal ini dapat meningkatkan penghematan bahan bakar dan kinerja dinamis kendaraan dengan lebih menyesuaikan kondisi pengoperasian mesin dengan skenario penggerak variabel[2].

Transmisi variabel kontinu setengah toroidal (CVT) dianggap sebagai powertrain kendaraan. Efisiensi sensitif terhadap geometrinya, dan variasi geometrinya dapat menyebabkan pengurangan FC kendaraan[3].

Dalam studi tersebut, beberapa alat analisis reliabilitas seperti mode kegagalan, analisis efek dan kekritisan (FMEA) dan analisis pohon kesalahan (FTA) digunakan untuk mengidentifikasi kemungkinan mode kegagalan sistem CVT dan subsistemnya[4][1].

Analisis rantai energi terdiri dari tiga bagian: penggunaan energi langsung bersih, energi yang dibutuhkan untuk penggerak kendaraan; rantai langsung bruto, yang mencakup konsumsi energi langsung netto ditambah energi yang dibutuhkan untuk memproduksinya; dan, terakhir, rantai energi tidak langsung, yang mencakup konsumsi energi untuk produksi, pemeliharaan, dan pengoperasian infrastruktur plus pembuatan kendaraannya[5].

Meskipun analisis distribusi beban dan kecepatan slip pada sabuk v logam CVT penting untuk dievaluasi peningkatan kinerjanya, akan sulit untuk mengembangkan model simulasi untuk menganalisis transmisi daya dengan sabuk CVT karena struktur sabuk yang kompleks[6].

\section{METODE}

Metode yang dipakai pada penelitian ini adalah Library Research method yaitu dengan pengambilan data melalui literatur. Penelitian ini dilakukan dengan cara mengidentifikasi bagianbagian dari kendaraan bermotor. Kemudian menghitung kompresi transmisi dan menganalisa terhadap CVT dan melakukan perhitungan serta pengukuran.

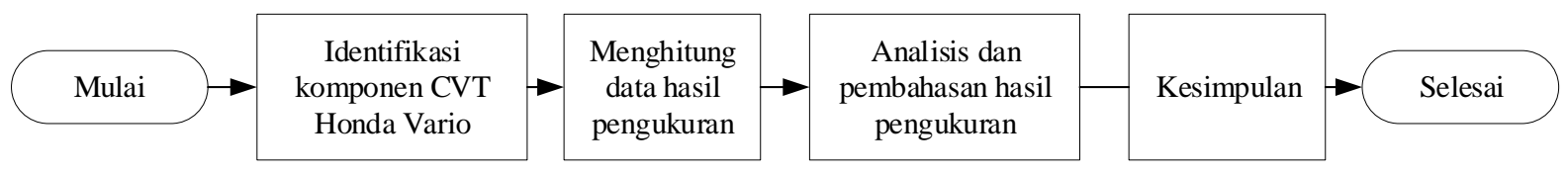

Gambar 1. Alir penelitian.

\section{HASIL DAN PEMBAHASAN}

Dalam pembahasan analisis daya terhadap torsi, supaya hasilnya maksimal, perhitungannya disesuaikan dengan desain yang telah dibuat. Meskipun angka-angka ini relatif rendah dibandingkan dengan transmisi manual standar (perkiraan efisiensi mekanis 97\%), perlu dicatat bahwa ketika digabungkan dengan mesin pembakaran internal, kemampuan CVT untuk memungkinkan mesin beroperasi lebih efisien dengan memberikan penghematan bahan bakar yang signifikan[7].

3.1 Perhitungan daya terhadap torsi.

$>$ Daya maksimum yang ditransmisikan 


$$
\begin{aligned}
& n_{1}=8500 \mathrm{rpm} \\
& P=\frac{n \cdot f c \cdot r}{9,74 \cdot 10^{5}} \\
& P=\frac{8500 \cdot 60,6 \cdot 15}{9,74 \cdot 10^{5}} \\
& p=7,93(\mathrm{~kW})
\end{aligned}
$$

Daya maksimum kecepatan terhadap daya yang dihasilkan, dimana setiap perubahan RPM berdampak pada perubahan daya.

Tabel 1. Perhitungan daya

\begin{tabular}{cr}
\hline $\mathbf{R P M}$ & $\mathbf{P}(\mathbf{k W})$ \\
\hline 1500 & 0.032340862 \\
2000 & 0.095482546 \\
2500 & 0.227156057 \\
3000 & 0.364989733 \\
3500 & 0.565965092 \\
4000 & 0.831622177 \\
4500 & 1.157340862 \\
5000 & 1.593942505 \\
5500 & 2.185318275 \\
6000 & 2.735112936 \\
6500 & 3.583675565 \\
7000 & 4.333675565 \\
7500 & 5.359342916 \\
8000 & 6.616016427 \\
8500 & 7.93275154
\end{tabular}

$\mathrm{Fc}=1,2$ (untuk daya maksimum yang diperlukan).

Momen daya maksimum yang bekerja.

$$
\begin{aligned}
& P_{d}=f_{c} \cdot P(k W) \\
& P_{d}=7,93 \times 1,2=9,5(\mathrm{~kW})
\end{aligned}
$$

Momen daya maksimum yang diakselerasikan.

$$
\begin{aligned}
& T=9,74 \times 10^{5} \times \frac{P_{d}}{n_{1}} \\
& \mathrm{~T}=9,74 \times 10^{5} \times \frac{9,5}{8500} \\
& \mathrm{~T}=10,68(\mathrm{~kg} \cdot \mathrm{mm})
\end{aligned}
$$

Dikonversikan ke (Nm) dikalikan 0,0098 menjadi 10,6 (Nm). 
Bagas Imam Priambodo, Hilman Sholih, Firmansyah Azharul

PERHITUNGAN KOMPRESI TRANSMISI (CONTINUOUSLY VARIABLE

TRANSMISSION) PADA SEPEDA MOTOR MATIC 150 CC

Tabel 2. Perhitungan daya terhadap torsi

\begin{tabular}{ll}
\hline RPM & T (Nm) \\
\hline 1500 & 0.24696 \\
2000 & 0.54684 \\
2500 & 1.04076 \\
3000 & 1.39356 \\
3500 & 1.8522 \\
4000 & 2.3814 \\
4500 & 2.94588 \\
5000 & 3.65148 \\
5500 & 4.55112 \\
6000 & 5.22144 \\
6500 & 6.31512 \\
7000 & 7.09128 \\
7500 & 8.18496 \\
8000 & 9.47268 \\
8500 & 10.68984 \\
\hline
\end{tabular}

\subsection{Perhitungan poros}

Beban pada poros yang dipergunakan adalah baja yang difinishing dingin (S45C-D) dengan kekuatan tarik $=53 \mathrm{~kg} / \mathrm{mm}^{2}$

$S f_{1} 6.0$ (harga 6.0 untuk bahan $S-C$ pengaruh masa dan baja paduan)

$S f_{2}=1.5$ (harga 1.5 merupakan faktor yang lain)

Adapun tegangan geser yang diizinkan adalah:

$$
\tau_{a}=\frac{\sigma_{B}}{S f_{1} \times S f_{2}}=\frac{53}{9}=5,8 \mathrm{~kg} / \mathrm{mm}^{2}
$$

Diameter poros.

$d_{s}=\left[\frac{5,1}{\tau_{a}} K_{t} \cdot C_{b} \cdot K\right] 1 / 3$

Dimana:

$$
\begin{aligned}
& K_{t}=2,0 \text { (faktor koreksi untuk menentukan momen putar) } \\
& C_{b}=1,5 \text { (faktor pada beban lentur) } \\
& d_{s}=\left[\frac{5,1}{5,8} \cdot 2,0 \cdot 1,5 \cdot 1090\right]^{1 / 3} \\
& \text { Diameter poros } d_{s}=(14,21 \mathrm{~mm})
\end{aligned}
$$

Maka didapat diameter poros yang direncanakan adalah $15 \mathrm{~mm}$ dengan bahan batang baja yang difinis dingin (S45C-D). 
3.3 Gaya sentrifugal pada CVT

$$
\begin{aligned}
& F c=m \frac{V^{2}}{r} \\
& \mathrm{~m}=15 \text { Gram } \times 6=90 \text { gram }=0,09 \mathrm{~kg} \\
& \mathrm{~V}=8500 \mathrm{rpm} \text { radius } 1 \text { meter } 890 \mathrm{~m} / \mathrm{s} \\
& \mathrm{r}=116 \mathrm{~mm}=0,116 \mathrm{~m} \\
& =0,09 \cdot \frac{890^{2}}{0,116} \cdot 0,0098 \\
& =60,6(\mathrm{Nm})
\end{aligned}
$$

Tabel 3. Gaya sentrifugal pada CVT

\begin{tabular}{cc}
\hline RPM & Fc (Nm) \\
\hline 1500 & 1,4 \\
2000 & 3,1 \\
2500 & 5,9 \\
3000 & 7,6 \\
3500 & 10,5 \\
4000 & 13,5 \\
4500 & 16,7 \\
5000 & 20,7 \\
5500 & 25,8 \\
6000 & 29,6 \\
6500 & 35,8 \\
7000 & 40,2 \\
7500 & 46,4 \\
8000 & 53,7 \\
8500 & 60,6 \\
\hline
\end{tabular}

3.4 Putaran terhadap perpindahan.

Putaran terhadap gaya sentrifugal awalnya diukur dari jarak antara primary fixed sheave dan primary sliding sheave ukurannya $36 \mathrm{~mm}$ pada putaran 0 RPM atau pada saat mesin tidak dihidupkan. Dari tabel 3 pada saat mesin dihidupkan pada saat putaran 1500 RPM gaya sentrifugal yang dihasilkan adalah $1,4(\mathrm{Nm})$.

$$
1,4-36=34,6(\mathrm{~mm}) \text {. }
$$

Pada saat putaran maksimum 8500 RPM gaya sentrifugal yang dihasilkan adalah 60,6 (Nm).

$$
60,6-36=24,6(\mathrm{~mm}) \text {. }
$$

Tabel 4. Putaran terhadap perpindahan

\begin{tabular}{cc}
\hline $\mathbf{F c}(\mathbf{N m})$ & $\mathbf{M m}$ \\
\hline 1,4 & 34,6 \\
3,1 & 32,9 \\
5,9 & 30,1 \\
7,9 & 28,4
\end{tabular}




\begin{tabular}{cc}
\hline $\mathbf{F c}(\mathbf{N m})$ & $\mathbf{M m}$ \\
\hline 10,5 & 25,5 \\
13,5 & 22,5 \\
16,7 & 19,3 \\
20,7 & 15,3 \\
25,8 & 10,2 \\
29,6 & 6,4 \\
35,8 & 0,2 \\
40,2 & 4,2 \\
46,4 & 10,4 \\
53,7 & 17,7 \\
60,6 & 24,6 \\
\hline
\end{tabular}

\section{SIMPULAN}

Dari analisa perhitungan yang telah dilakukan, torsi sesuai spesifikasi mesin 12,8 (Nm), ketika dilakukan perhitungan secara manual, didapatkan hasil yang hampir mendekati 10,6 (Nm). Poros penggerak pulley driven dari perhitungan didapatkan ukuran sebesar 14,21 (mm), dari dimensi yang sudah diukur sebelumnya sebesar $15 \mathrm{~mm}$. Gaya sentrifugal pada pulley driven dengan ukuran roller 15 Gram pada putaran maksimum RPM 8500 mampu menghasilkan gaya sentrifugal sebesar 60,6 (Nm). Putaran terhadap gaya sentrifugal dari jarak antara primary fixed sheave dan primary sliding sheave pada saat idle RPM 1500 jaraknya 34,6 (mm) dan pada saat RPM 8500 jaraknya 24,6 mm.

\section{REFERENSI}

[1] S. Hartini and R. Adityo, "ANALISIS MODA KEGAGALAN DENGAN PENDEKATAN RELIABILITY CENTERED MAINTENANCE (RCM) (Studi kasus Baking Section Mesin Imfori PT Nissin Biskuit Indonesia)," J@Ti Undip J. Tek. Ind., vol. 1, no. 3, pp. 53-61, 2012, doi: 10.12777/jati.1.3.53-61.

[2] N. Srivastava and I. Haque, "A review on belt and chain continuously variable transmissions (CVT): Dynamics and control," Mech. Mach. Theory, vol. 44, no. 1, pp. 19-41, 2009, doi: 10.1016/j.mechmachtheory.2008.06.007.

[3] C. V. Transmission, "Application of Multi-objective Optimization for Optimization of Halftoroidal Continuously Variable Transmission," Int. J. Eng., vol. 27, no. 9 (C), pp. 1449-1456, 2014, doi: 10.5829/idosi.ije.2014.27.09c.15.

[4] J. S. You and W. F. Wu, "Design improvement through reliability analysis of belt-type CVT systems for scooters," Adv. Mater. Res., vol. 291-294, no. February, pp. 2215-2221, 2011, doi: 10.4028/www.scientific.net/AMR.291-294.2215.

[5] M. Simonsen and H. J. Walnum, "Energy chain analysis of passenger car transport," Energies, vol. 4, no. 2, pp. 324-351, 2011, doi: 10.3390/en4020324.

[6] I. Tarutani, H. Tani, and Y. Nagasawa, "Analysis of the Power Transmission Characteristics of 
a Metal V-belt Type CVT," Tech. J. /R\&D Rev. Toyota CRDL, vol. Vol.4 No.3, no. Special Issue: Basic Analysis Towards Further Development of Continuously Variable Transmission, pp. 6-13, 2005.

[7] C. A. Bell, "Constant Power - Continuously Variable Optimisation and Simulation," PHD thesis Brunel Univ., pp. 1-290, 2011. 